\title{
A high performance electrode material for lithium ion batteries derived from a cobalt-based coordination polymer
}

Tehseen Ilyas, ${ }^{1}$ Fatima Nasim, ${ }^{1}$ Mohammad Choucair, ${ }^{2}$ Shafiq Ullah, ${ }^{1}$ Muhammad Abdullah Khan, ${ }^{3}$ Amin Badshah, ${ }^{1}$ and Muhammad Arif Nadeem ${ }^{1 *}$

${ }^{1}$ Catalysis and Nanomaterials Lab 27, Department of Chemistry, Quaid-i-Azam University, Islamabad 45320, Pakistan

${ }^{2}$ School of Chemistry, University of Sydney, Sydney, Australia 2006

${ }^{3}$ Wolfson Catalysis Centre, Department of Chemistry, University of Oxford, South Parks Road, Oxford, UK

*Corresponding Author: manadeem@qau.edu.pk, +925190642062

\begin{abstract}
A carbon rich co-ordination polymer, $[\mathrm{Co}(\mathrm{fa})(\mathrm{bpy})]_{\mathrm{n}}(\mathbf{1})$, based on formic acid (fa) and an auxiliary ligand 4,4-bipyridine (bpy) is utilized as a single source precursor to an exceptional lithium-ion battery electrode material. Compound $\mathbf{1}$ consists of cobalt-formate chains connected via bipyridine ligands into a three dimensional lattice. A cobalt-oxide/carbon composite material is obtained by the controlled carbonization of $\mathbf{1}$ at $900{ }^{\circ} \mathrm{C}$. Morphological, structural, and chemical analysis of the composite is carried out with HR-TEM, XPS and PXRD techniques. This new composite material demonstrates a high specific capacity of $1080 \mathrm{mAhg}^{-1}$, a coulombic efficiency of 94\%, and a stable cyclic retention for upto 30 cycles. The electrochemical properties of this new material are discussed in relation to the structural and chemical characteristics of precursor dependence of the carbonized hybrid nanomaterial.
\end{abstract}

Keywords: coordination polymer; lithium ion batteries; electrode material; carbon composite 


\section{Introduction}

Portable Energy devices are being ubiquitous in everyday tools ranging from cell phones to laptops and electric vehicles to hybrid electric vehicles. ${ }^{1}$ Lithium ion batteries (LIBs), an example of a portable energy device, are the current technology of choice because of their high energy density and efficiency, long life span ${ }^{[1]}$ and being relatively amiable to the environment. ${ }^{[2]}$ For commercial use of batteries in electric vehicles (EV) or hybrid electric vehicles(HEV), efforts are still in progress to develop cheap and efficient electrode materials ${ }^{[3]}$ which can show more durability and have a long cycle life ${ }^{[4]}$. To achieve these goals, a great attention has been done on tuning the electrode material via composition, shape and morphology of the particles at the micro and nanoscale. ${ }^{[5]}$ Various transition-metal oxides have been extensively studied as electrode materials for LIBs due to their high theoretical capacity and cost effectiveness. ${ }^{[6]}$ In this regard, different metal oxides, $\mathrm{CoO},{ }^{[7]} \mathrm{Co}_{3} \mathrm{O}_{4},{ }^{[8]} \mathrm{Fe}_{3} \mathrm{O}_{4},{ }^{[9]} \mathrm{SnO}_{2},{ }^{[10]} \mathrm{ZnO}$, $\mathrm{In}_{2} \mathrm{O}_{3}$, and $\mathrm{NiO}{ }^{[11]}$ have been synthesized and subsequently utilized as the anode materials in lithium-ion batteries.

Metal Organic frameworks are now well established new type of porous material having metal oxide as inorganic nodes connected through organic linkers that often support large pore volumes and high surface area. Their modular makeup enables the structures to be tunable and allows to tailor their properties. ${ }^{[12]}$ This textural richness of both metal oxide and carbon source makes MOFs as ideal precursors for the preparation of metal oxide/carbon composite materials. The porous structure of the MOF precursor assists the formation of composite materials that also features a high surface to volume ratio, surface area, and void spaces. Recent reports have shown the potential of MOFs to be used as a single source precursor for the synthesis of electrode materials for LIB materials. Buxue Wang et al. for example, followed a coating pyrolysis 
strategy to synthesize a nanoscale yolk/shell octahedron of $\mathrm{Cr}_{2} \mathrm{O}_{3} @ \mathrm{TiO}_{2} \cdot{ }^{[13]} \mathrm{MIL}-101(\mathrm{Cr}-\mathrm{MOF})$ was utilized as precursor and morphology was demonstrated using SEM and TEM techniques. Comparison of bare $\mathrm{Cr}_{2} \mathrm{O}_{3}$ and coated $\mathrm{Cr}_{2} \mathrm{O}_{3}$ used as anode material in LIB's revealed that electrochemical performance and reversible capacity of coated $\mathrm{Cr}_{2} \mathrm{O}_{3}$ was much higher than bare $\mathrm{Cr}_{2} \mathrm{O}_{3}$. Likewise, Jun Song Chen et al. developed a facile hydrothermal method to fabricate different morphologies of $\mathrm{Co}_{3} \mathrm{O}_{4}$ specifically nanocubes, hexagonal nanodisks, as well as hierarchical nano-flowers. ${ }^{[14]}$ Amongst all the three obtained $\mathrm{Co}_{3} \mathrm{O}_{4}$ samples, nano-flowers exhibited the best performance when evaluated as anode material in LIB's. This also provides insight about the effect of morphology on electrochemical lithium storage properties. Xia Yang et al. have also fabricated a hetero-bimetallic MOF via cation exchange mechanism. ${ }^{[15]}$ The bimetallic MOF was subsequently converted into a porous composite material. The obtained bimetallic composite material was used as an anode material for lithium ion batteries which exhibited an electrochemical performance of $774 \mathrm{mAhg}^{-1}$ after 120 cycles at $500 \mathrm{mAg}^{-1}$.

As a continuation of our previous work, we are focusing on heat treatment of selected MOFs and optimization of carbonization temperature to obtain best material for LIBs applications. Recently, we have reported cobalt oxide/NCNT composite material which was obtained by the carbonization of ZIF-12. The cobalt oxide/NCNT composite material showed an excellent lithium charge/discharge and storage, retaining 95\% capacity after 50 cycles and a reversible capacity of ca.1100 $\mathrm{mA} \mathrm{h} \mathrm{g}^{-1} \cdot{ }^{[16]}$ We have selected a number of porous and non-porous cobalt based MOFs from the literature and carbonized at various temperatures ranging from $600{ }^{\circ} \mathrm{C}$ to $900{ }^{\circ} \mathrm{C}$. In current work, we obtained Co-oxide/carbon composite which on testing reveals high performance activity as an anode material for LIBs. This composite material is obtained by 
carbonization of a carbon rich cobalt based microporous coordination polymer $[\mathrm{Co}(\mathrm{fa})(\mathrm{bpy})]_{\mathrm{n}}(\mathbf{1})$

at $900{ }^{\circ} \mathrm{C}$. The compound $\mathbf{1}$ was initially reported by Xin-Yi et al. ${ }^{[17]}$

\section{Experimental}

\subsection{Synthesis}

All reagents mentioned in the synthetic procedure were of analytical grade and used without any further purification. A solution of $\mathrm{Co}\left(\mathrm{NO}_{3}\right)_{2} \cdot 6 \mathrm{H}_{2} \mathrm{O}(1 \mathrm{mmol})$ in $N, N$-dimethylformamide (DMF, $7 \mathrm{ml})$, is mixed with the another solution of 4,4-bipyridine $(0.5 \mathrm{mmol})$ in DMF $(7 \mathrm{ml})$. The mixture was transferred into an air-tight glass vial, kept in an oven and maintained at $90{ }^{\circ} \mathrm{C}$ for 72 hours. The mixture was allowed to cool at room temperature and the resulting pink crystals were filtered off, washed several times with DMF and absolute ethanol to remove any unreacted residue, and dried at $60{ }^{\circ} \mathrm{C}$ to give compound $\mathbf{1}$.

The synthesized and vacuum evacuated compound 1 (300 mg) was transferred into a ceramic boat which was placed in a quartz tube fixed in a tube furnace (Nabertherm B 180). Initially air was flushed away by continuous flow of Argon for $60 \mathrm{~min}$ followed by heating at $900{ }^{\circ} \mathrm{C}$ for $6 \mathrm{~h}$ to obtain the cobalt-oxides/carbon composite material; yield ca. 86.6\% (260 mg).

\subsection{Structural and Chemical Characterization}

Powder X-ray diffraction (PXRD) measurements were carried out on a PANalytical X-ray diffractometer (X'Pert PRO 3040/60) at a scan rate of $0.015 \mathrm{~s}^{-1}$ with $\mathrm{Cu} \mathrm{K} \alpha(\lambda=1.544206 \AA)$ radiation generated at $40 \mathrm{kV}$ voltage and $30 \mathrm{~mA}$ current.

The Co-oxides particle size and shape was determined by Transmission Electron Microscopy (TEM) with an FEI Titan 80-300 CT transmission electron microscopeat an acceleration voltage of $300 \mathrm{kV}$. 
X-ray photoelectron spectroscopy (XPS) measurements were conducted with an ESCALAB250Xi (Thermo Scientific, UK) instrument with a background vacuum better than $2 \times 10^{-9}$ mbar. Mono-chromated $\mathrm{Al} \mathrm{K}_{\alpha}($ energy $\mathrm{h} v=1486.68 \mathrm{eV})$ radiation at a power of $164 \mathrm{~W}$ (10.8 mA and $15.2 \mathrm{kV}$ ) with a spot size of $500 \mu \mathrm{m}$ was used for analysis. The photoelectron take-off angle was $90^{\circ}$ and the pass energy was $100 \mathrm{eV}$ for the survey and $20 \mathrm{eV}$ for narrow region scans. Curve fitting was performed using the Scienta ESCA300 data-system software.

\subsection{Electrochemical Characterization}

The electrochemical performance of the synthesized Co-oxide/carbon composite was evaluated by galvanostatic charge-discharge testing against lithium as the counter electrode. The working electrodes were made by a slurry coating procedure. The slurry was prepared by sonicating 80 wt.\% of Co-oxide/carbon composite material, 10 wt.\% of acetylene black and 10 wt.\% of poly(vinylidenefluoride) PVDF binder in N-methyl pyrolidinone solvent. Slurry was uniformly coated on the copper foil current collector. The electrodes were dried in a vacuum oven at $100{ }^{\circ} \mathrm{C}$ for 12 hours. A CR-2025type coin cell was fabricated in an argon filled glove box using polyethylene as a separator and $1 \mathrm{~mol} / \mathrm{L} \mathrm{LiPF}_{6}$ in ethylene carbonate/dimethyl carbonate (1:1) as the electrolyte. The electrochemical discharge/charge tests of the sample were performed at voltage limits of 3.0-0.01 V versus $\mathrm{Li}^{-\mathrm{Li}^{+}}$and the mass loading of material was $c a .1 \mathrm{mg} \mathrm{cm}^{-2}$.

\section{Results and Discussion}

\subsection{Structural analysis}

Because the compound $\mathbf{1}$ has been reported in literature, the structural analysis is briefly discussed. The compound $\mathbf{1}$ consists of cobalt ${ }^{\mathrm{II}}$ formate chains that are further connected through bipyridine (bpy) linkers. There is one crystallographically unique $\mathrm{Co}^{\mathrm{II}}$ ion with an octahedral geometry is present. Each cobalt ion is bridged to six neighboring cobalt atoms via the bridging 
formate and bpy linkers. Each formate ligand bridges two Co atoms at a distance of $5.897 \AA$ whilst each bpy bridges the two Co at a distance of $11.282 \AA$. The two pyridine rings of each bpy ligand are not in plane, and the two benzene rings are twisted at a torsion angle of $45.37^{\circ}$. The phase purity of $\mathbf{1}$ was confirmed by PXRD.

The phase purity of the metal-oxide in composite material was confirmed by PXRD (Figure 1). The PXRD pattern revealed that composite consists of a mixture of $\mathrm{Co}_{3} \mathrm{O}_{4}, \mathrm{Co}_{2} \mathrm{O}_{3}$ and $\mathrm{CoO}$. PXRD peaks are observed for cubic phase $\mathrm{Co}_{3} \mathrm{O}_{4}$ at $2 \theta=19.00^{\circ}, 31.27^{\circ}, 38.54^{\circ}, 44.81^{\circ}$, and $59.30^{\circ}$ corresponding to (111), (220), (222), (400), and (511) diffraction planes respectively (JCPDS No: 00-042-1476); hexagonal geometry $\mathrm{Co}_{2} \mathrm{O}_{3}$ with peaks at $2 \theta=31.13^{\circ}$, and $58.76^{\circ}$ corresponding to diffraction planes (111) and (200) respectively (JCPDS No:00-002-0770); and cubic $\mathrm{CoO}$ with peaks at $2 \theta=36.47^{\circ}$, and $42.30^{\circ}$ corresponding to diffraction planes (111) and (200) respectively (JCPDS No: 01-071-1178).

The TEM images of composite show irregular shaped cobalt-oxide nanoparticles encapsulated within a carbon matrix, figure 2(a).The crystalline cobalt-oxide nanoparticles were distinguished from the encapsulating amorphous carbon material using select area electron diffraction (SAED) (Inset of figure 2b). This interconnected heterostructure is an ideal for use as an electrode material in LIBs because the carbon coating/wrapping of the nano size cobalt-oxide particles: (1) assists in buffering the volume changes associated with the insertion and de-insertion of $\mathrm{Li}^{+}$, (2) maintains the electrode integrity and conductivity during the electrochemical transport of $\mathrm{Li}^{+}$, and (3) shortens the lithiation pathway through enhanced contact between the active materials and electrolyte. ${ }^{[18]}$

\subsection{Chemical composition of composite}


X-ray photoelectron spectroscopy (XPS) was used to quantitatively examine the surface chemistry of composite, Figure 3 . The corresponding in-depth analysis of the Co $2 p_{3}$ core line spectra (Figure 3d) confirmed a peak within the overlapping binding energy region of cobalt oxides $\left(\mathrm{Co}_{2} \mathrm{O}_{3}, \mathrm{CoO}, \mathrm{Co}_{3} \mathrm{O}_{4}\right)$ at $780.2 \mathrm{eV}$ (corresponding an amount of cobalt in cobalt-oxides of $\sim 46$ wt.\% $)^{[19],[20],[21]}$. Hence, more than one type of oxide was present within the sample. Approximately $65 \mathrm{wt} . \%$ of the sample contained cobalt oxides, with 25 wt.\% corresponding to mainly graphitic carbon $(285.0 \mathrm{eV})$ with some amount of carbidic $(283.1 \mathrm{eV})$ and oxidized carbon (286.6 and $288.2 \mathrm{eV}$ ), and less than $10 \mathrm{wt} . \%$ attributed to organic residue. Very small amount of chloride were also detected embedded on the surface.

\subsection{Lithium-ion Battery Testing}

Charge-discharge curves at a rate of $0.1 \mathrm{Ag}^{-1}$ are shown in Figure 4(a).The charging curve for both the $1^{\text {st }}$ and $2^{\text {nd }}$ cycle shows that as the voltage increases, charging capacity increases linearly which is typical of insertion of $\mathrm{Li}^{+}$into cobalt-oxides. The presence of a plateau around $1.0 \mathrm{~V}$ shows the presence of cobalt oxide. The plateau weakens in the subsequent cycles which may be due to non-reversible formation of Co (0). The presence of this plateau suggests the conversion mechanism. The calculated values of specific capacity are $1080 \mathrm{mAhg}^{-1}$ and $1025 \mathrm{mAhg}^{-1}$ for the first and second cycle, respectively. The estimated specific capacity value (1080 mAhg $\left.{ }^{-1}\right)$, is $21.34 \%$ greater than the theoretical capacity of bulk $\mathrm{Co}_{3} \mathrm{O}_{4}\left(890 \mathrm{mAhg}^{-1}\right)^{[22]}$. In order to evaluate the efficiency of composite material, we have also calcined the compound $\mathbf{1}$ in air to obtain carbon free cobalt oxide nano particles and the charge discharge curves were also recorded for pure Co-oxide particles figure 4(d). The cobalt oxide particles delivered a charging capacity of $1000 \mathrm{Ah} / \mathrm{gm}$ in first cycle, and curtailed to $720 \mathrm{mAh} / \mathrm{gm}$ in $2^{\text {nd }}$ discharge cycle. However, embedded carbon in cobalt oxide particles delivered $1080 \mathrm{mAh} / \mathrm{gm}$ and $1020 \mathrm{mAh} / \mathrm{gm}$ in $1^{\text {st }}$ and 
$2^{\text {nd }}$ cycle respectively. These results indicates the additional beneficial effect of porous embedded carbon in voids of cobalt oxides particles. The higher capacity of the composite material can be ascribed to the structural defects and presence of nitrogen and oxygen functional groups which facilitates the insertion and de-insertion into the voids free spaces. These groups and high surface area facilitate the decomposition of the electrolyte which results in higher initial capacity.

As the voltage drops from $3 \mathrm{~V}$ to $1.3 \mathrm{~V}$, the appearance of first plateau is observed which is ascribed to ohmic polarization, and formation of solid electrolyte interface. Due to reactions at electrolyte interface, a second plateau appears between $1.3 \mathrm{~V}$ to $0.3 \mathrm{~V}$. The end of discharge cycle upto cut-off voltage $(0.01 \mathrm{~V})$ is due to mass transport limitation which causes a deformation of the material structure and formation of Co metal scattered in a matrix of $\mathrm{Li}_{2} \mathrm{O}$ [i.e. $\left.\mathrm{Co}_{3} \mathrm{O}_{4}(s)+8 \mathrm{Li}(s) \rightarrow 3 \mathrm{Co}(s)+4 \mathrm{Li}_{2} \mathrm{O}(s)\right]^{[23]},{ }^{[24]}$ due to continuous insertion and de-insertion of $\mathrm{Li}^{+}$. The columbic efficiency remains almost same i.e. $94 \%$ in both cycles, which is the highest amongst similar reported materials. ${ }^{[25]}$

Figure 4(b) shows the relation between charge capacity and cycle numbers. The electrode delivers a capacity of $1080 \mathrm{mAhg}^{-1}$ and $980 \mathrm{mAhg}^{-1}$ at $1^{\text {st }}$ cycle and after 30 cycles, respectively. The maximum value of columbic efficiency achieved was 92\%. This implies complete chemical reaction between electrode material and $\mathrm{Li}^{+}$. As observed in figure 2a, the $\mathrm{CoO} x$ nanoparticles preferentially embedded into the pores of the carbon material, the carbon framework can effectively prevent $\mathrm{CoO} x$ nano particles in the carbon matrix from aggregating, as well as provides a good conductivity. The porosity provides the enough space to buffer the volume change during the $\mathrm{Li}$-ion insertion and extraction reactions in $\mathrm{CoO} x$ nano particles. All of these factors above-mentioned can collectively enhance the cycling stability of composite material. 
To evaluate rate capability at various current densities, specific capacity was calculated and results are presented in Figure 4(c). The capacity obtained at each current rate remains constant and stable, 1000, 980, 960, 900 and $780 \mathrm{mAhg}^{-1}$ capacities are delivered at 0.1, 0.2, 0.3, 1 and 5 $\mathrm{Ag}^{-1}$ respectively for 30 cycles. At the current rate of $0.1 \mathrm{Ag}^{-1}$, specific capacity returned back to $1000 \mathrm{mAhg}^{-1}$ indicating the $100 \%$ capacity retention. Excellent rate capability can be explained by the short diffusion path for $\mathrm{Li}^{+}$ions in electrolyte. During the $\mathrm{Li}$-ion insertion/extraction reaction, $\mathrm{CoO} x$ embedded in the carbon matrix have more surface area available for Li-ion diffusion and a shorter lithium-ion diffusion pathway. The transfer of electrons to the current collector is also fast enough throughout carbon matrix. These parameters result in a good rate capacity in the applications of practical lithium-ion batteries. ${ }^{[26]}$ All these required properties of the Co-oxide/carbon composite are due to the in situ formation of porous carbon and Co-oxide from a single source precursor (MOF), because carbonization at elevated temperature result in the evolution of gaseous products which leave behind pores in the composite material.

A comparison of recently reported different electrode materials and their LIBs performances is summarized in table 1.

\section{Conclusions}

Crystalline cobalt-oxide nanoparticles were generated within an encapsulating carbon matrix. This electrochemically active composite was derived from a 3-dimentional cobalt based coordination polymer. The composite demonstrated an excellent reversible capacity of $\sim 1100$ $\mathrm{mAh} / \mathrm{g}^{-1}$, which is a significant increase over the sum of the constituent materials, and maintained one of the highest cyclic performances of cobalt-oxide electrode materials. When taken together, these results represent highly desirable outcomes for use in lithium ion batteries. Essentially, the carbon material in the composite provides elastic buffer space to accommodate 
the volume expansion of oxide particles during $\mathrm{Li}$ insertion/extraction, thus, preventing accumulation of Co-oxides and cracking of the electrode material upon cycling. This unique approach of carbonizing a MOF precursor yields high performance electrode material for Li-ion batteries. This technique can be extended to other binary and ternary metal oxides to explore the possibility to design and achieve high performance electrode materials for LIB’s.

\section{Acknowledgements}

The work was financially supported by Higher Education Commission (HEC) of Pakistan (No. 20-2704/NRPU/R\&D/HEC/12). We would also like to thank Dr. Matthias Zeller of Youngstown State University, Youngstown, Ohio, USA, for single crystal data collection and structure refinement. The X-ray diffractometer at Youngstown University was funded by NSF Grant DMR-1337296. 


\section{References}

[1] B. Scrosati, J. Garche, J. Power Sources2010, 195, 2419.

[2] S.-L. Chou, J.-Z. Wang, H.-K. Liu, S.-X. Dou, J. Power Sources2008, 182, 359.

[3] Y. Wu, E. Rahm, R. Holze, J. Power Sources2003, 114, 228.

[4] C. He, S. Wu, N. Zhao, C. Shi, E. Liu, J. Li, ACS nano2013, 7, 4459.

[5] Y. Jin, L. Wang, Y. Shang, J. Gao, J. Li, X. He, Electrochim. Acta2015, 151, 109.

[6] P. Poizot, S. Laruelle, S. Grugeon, L. Dupont, J. Tarascon, Nature2000, 407, 496.

[7] Y. Sun, X. Hu, W. Luo, Y. Huang, J. Phys. Chem.C2012, 116, 20794.

[8] M. Reddy, G. Prithvi, K. P. Loh, B. Chowdari, ACS Appl.Mater.Interfaces2013, 6, 680.

[9] Y. Chen, H. Xia, L. Lu, J. Xue, J. Mater. Chem.2012, 22, 5006.

[10] L. Protesescu, A. J. Rossini, D. Kriegner, M. Valla, A. De Kergommeaux, M. Walter, K. V. Kravchyk, M. Nachtegaal, J. Stangl, B. Malaman, ACS Nano2014, 8, 2639.

[11] A. Banerjee, V. Aravindan, S. Bhatnagar, D. Mhamane, S. Madhavi, S. Ogale, NANO ENERGY2013, 2, 890.

[12] L. Song, J. Zhang, L. Sun, F. Xu, F. Li, H. Zhang, X. Si, C. Jiao, Z. Li, S. Liu, Energy Environ Sci2012, 5, 7508.

[13] B. Wang, Z. Wang, Y. Cui, Y. Yang, Z. Wang, B. Chen, G. Qian, Microporous Mesoporous Mater.2015, 203, 86.

[14] J. S. Chen, T. Zhu, Q. H. Hu, J. Gao, F. Su, S. Z. Qiao, X. W. Lou, ACS Appl. Mater. Interfaces2010, 2, 3628.

[15] X. Yang, Y.-B. Tang, X. Huang, H. T. Xue, W. P. Kang, W. Y. Li, T.-W. Ng, C.-S. Lee, J. Power Sources2015, 284, 109. 
[16] I. Khan, F. Nasim, M. Choucair, S. Ullah, A. Badshah, M. Nadeem, RSC Advances2016, 6, 1129.

[17] X.-Y. Wang, H.-Y. Wei, Z.-M. Wang, Z.-D. Chen, S. Gao, Inorg. Chem.2005, 44, 572.

[18] H.-j. Liu, S.-h. Bo, W.-j. Cui, F. Li, C.-X. Wang, Y.-y. Xia, Electrochim. Acta2008, 53, 6497.

[19] S. L. T. Andersson, R. F. Howe, J.Phys. Chem.1989, 93, 4913.

[20] N. McIntyre, M. Cook, Anal. Chem.1975, 47, 2208.

[21] N. McIntyre, D. Johnston, L. Coatsworth, R. Davidson, J. Brown, Surf. Interface Anal.1990, 15, 265.

[22] J. Guo, B. Jiang, X. Zhang, L. Tang, Y.-h. Wen, J. Mater. Chem. A2015, 3, 2251.

[23] Q. Su, J. Zhang, Y. Wu, G. Du, NANO ENERGY2014, 9, 264,

[24] W. Wen, J.-M. Wu, J.-P. Tu, J. Alloy Compd.2012, 513, 592.

[25] Q. Qu, T. Gao, H. Zheng, X. Li, H. Liu, M. Shen, J. Shao, H. Zheng, Carbon2015, 92, 119.

[26] W. Zhu, H. Huang, Y. Gan, X. Tao, Y. Xia, W. Zhang, Electrochim. Acta2014, 138, 376.

[27] K. Adjemian, S. Lee, S. Srinivasan, J. Benziger, A. Bocarsly, J. Electrochem. Soc.2002, 149, A256.

[28] X. Li, J. Liu, Y. Zhang, Y. Li, H. Liu, X. Meng, J. Yang, D. Geng, D. Wang, R. Li, J. Power Sources2012, 197, 238.

[29] Y. Tan, K. Zhu, D. Li, F. Bai, Y. Wei, P. Zhang, Chem. Eng. J.2014, 258, 93.

[30] H. Yue, Z. Shi, Q. Wang, Z. Cao, H. Dong, Y. Qiao, Y. Yin, S. Yang, ACS Appl. Mater.Interfaces2014, 6, 17067.

[31] Y. Xiao, P. Sun, M. Cao, ACS Nano2014, 8, 7846. 
[32] S. M. Abbas, S. T. Hussain, S. Ali, N. Ahmad, N. Ali, K. S. Munawar, Electrochim. Acta2013, 105, 481.

[33] B. Wang, Y. Wang, J. Park, H. Ahn, G. Wang, J. Alloy Compd.2011, 509, 7778.

[34] B.-C. Yu, J.-O. Lee, J. H. Song, C.-M. Park, C. K. Lee, H.-J. Sohn, J.Solid State Electrochem.2012, 16, 2631.

[35] J. Wang, B. Niu, G. Du, R. Zeng, Z. Chen, Z. Guo, S. Dou, Mater.Chem.Phys.2011, 126, 747.

[36] X.-Y. Xue, S. Yuan, L.-L. Xing, Z.-H. Chen, B. He, Y.-J. Chen, Chem. Commun.2011, 47, 4718.

[37] H. Wang, D. Ma, X. Huang, Y. Huang, X. Zhang, Sci.Reports2012, 2.

[38] Z.-L. Wang, D. Xu, H.-G. Wang, Z. Wu, X.-B. Zhang, Acs Nano2013, 7, 2422.

[39] X. l. Huang, R. z. Wang, D. Xu, Z. l. Wang, H. g. Wang, J. j. Xu, Z. Wu, Q. c. Liu, Y. Zhang, X. b. Zhang, Adv.Func. Mater.2013, 23, 4345.

[40] X.-l. Huang, J. Chai, T. Jiang, Y.-J. Wei, G. Chen, W.-q. Liu, D. Han, L. Niu, L. Wang, X.-b. Zhang, J. Mater. Chem.2012, 22, 3404.

[41] Y. Huang, X.-l. Huang, J.-s. Lian, D. Xu, L.-m. Wang, X.-b. Zhang, J. Mater. Chem.2012, 22, 2844.

[42] X.-l. Huang, X. Zhao, Z.-l. Wang, L.-m. Wang, X.-b. Zhang, J. Mater. Chem.2012, 22, 3764.

[43] H. Song, L. Shen, C. Wang, J. Mater. Chem. A2014, 2, 20597.

[44] H. Yue, Z. Shi, Q. Wang, Y. Ding, J. Zhang, N. Huo, S. Yang, RSC Advances2015, 5, 75653. 
[45] K. Wenelska, C. Neef, L. Schlestein, R. Klingeler, R. J. Kalenczuk, E. Mijowska, Chem. Phys. Lett. 2015, 635, 185.

[46] H. Huang, W. Zhu, X. Tao, Y. Xia, Z. Yu, J. Fang, Y. Gan, W. Zhang, ACS Appl. Mater.Interfaces2012, 4, 5974.

[47] J. Jiang, J. Liu, R. Ding, X. Ji, Y. Hu, X. Li, A. Hu, F. Wu, Z. Zhu, X. Huang, J. Phys. Chem. C2009, 114, 929.

[48] N. Yan, L. Hu, Y. Li, Y. Wang, H. Zhong, X. Hu, X. Kong, Q. Chen, J. Phys. Chem. C2012, 116, 7227, DOI: 10.1021/jp2126009.

[49] J. Guo, B. Jiang, X. Zhang, L. Tang, Y.-h. Wen, J. Mater. Chem. A2015, 3, 2251.

[50] M. Chen, X. Xia, J. Yin, Q. Chen, Electrochim. Acta2015, 160, 15. 


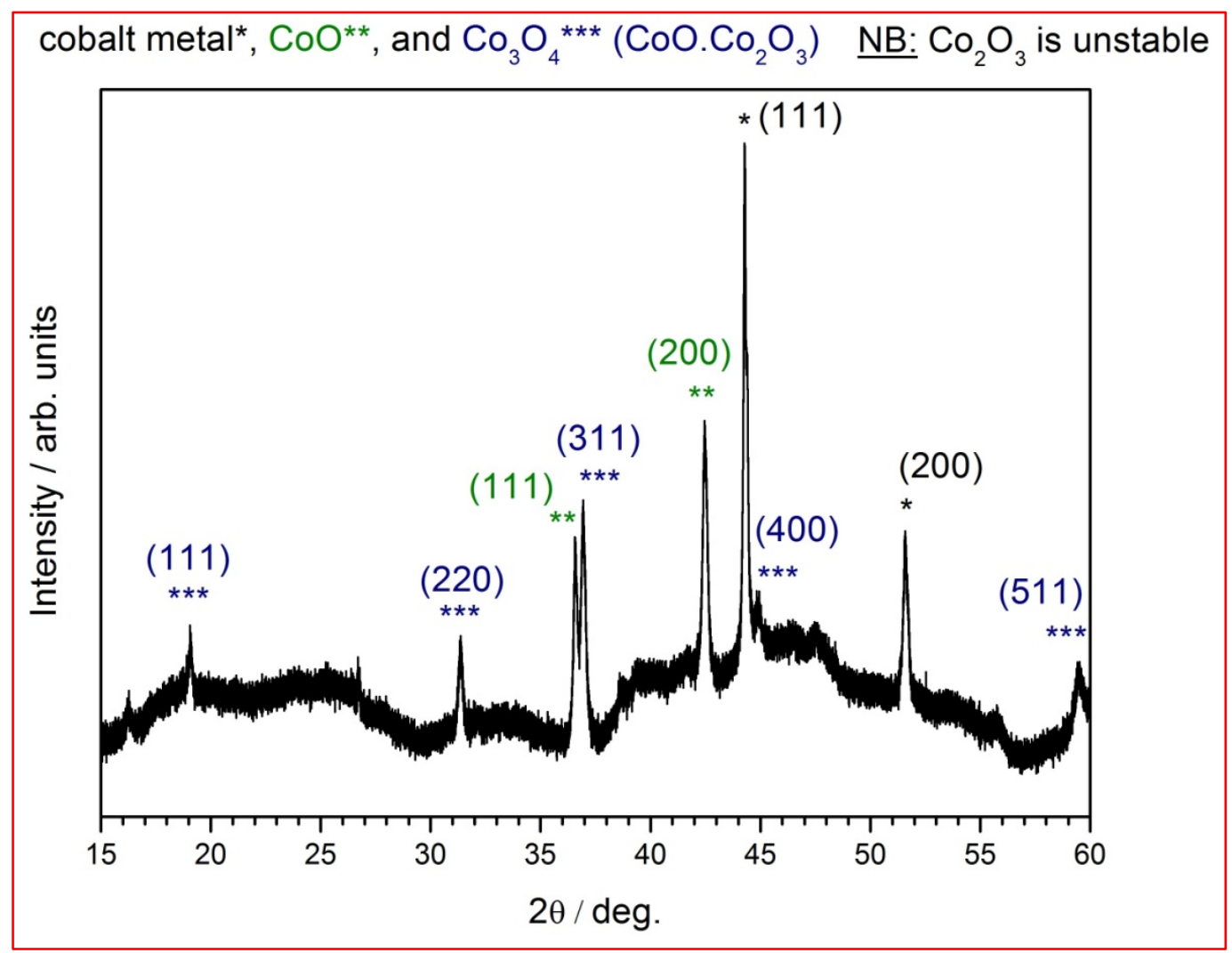

Figure 1. The PXRD pattern of Co-oxide/carbon composite 

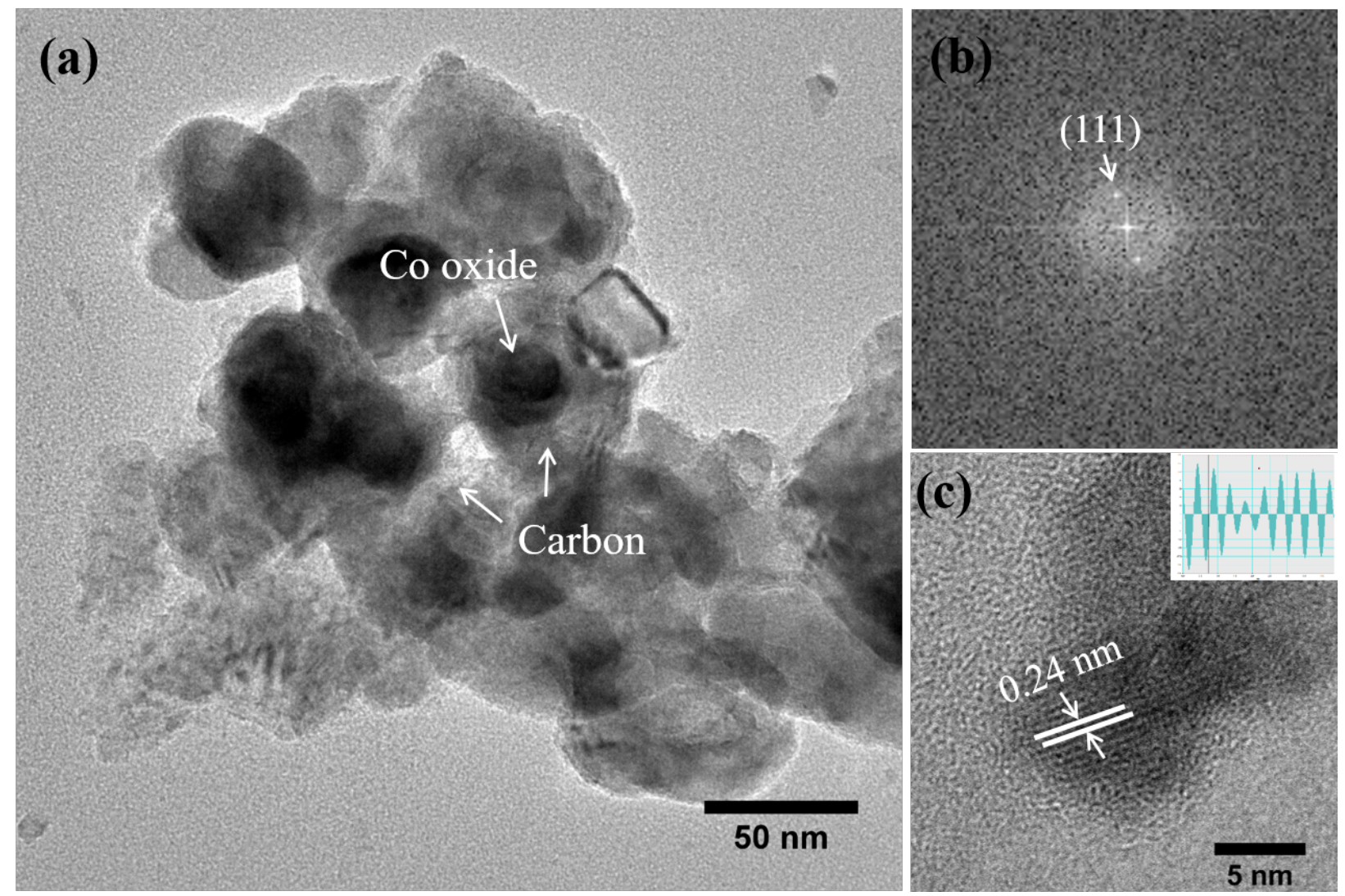

Figure 2. (a) TEM images of Co-oxide/carbon composite representing Co-oxide nanoparticles encapsulated within a carbon matrix(b) SAED images (c) HR-TEM of Co-oxide particle 


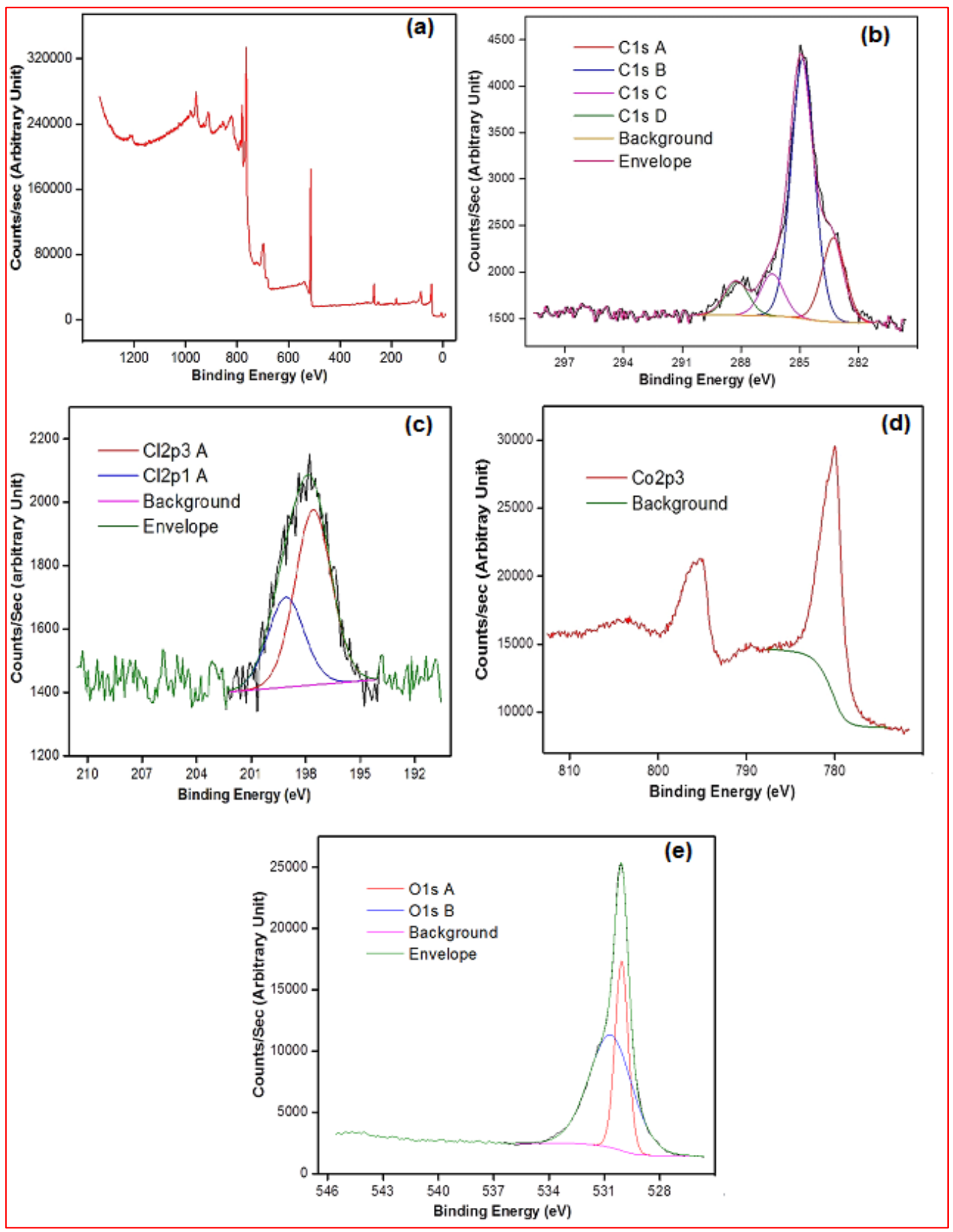

Figure 3. XPS graphs (a) Survey Scan XPS spectrum (b) C1s core line (c) Cl2p core line (d) Co 2p3 core lines (e) O1s core lines 

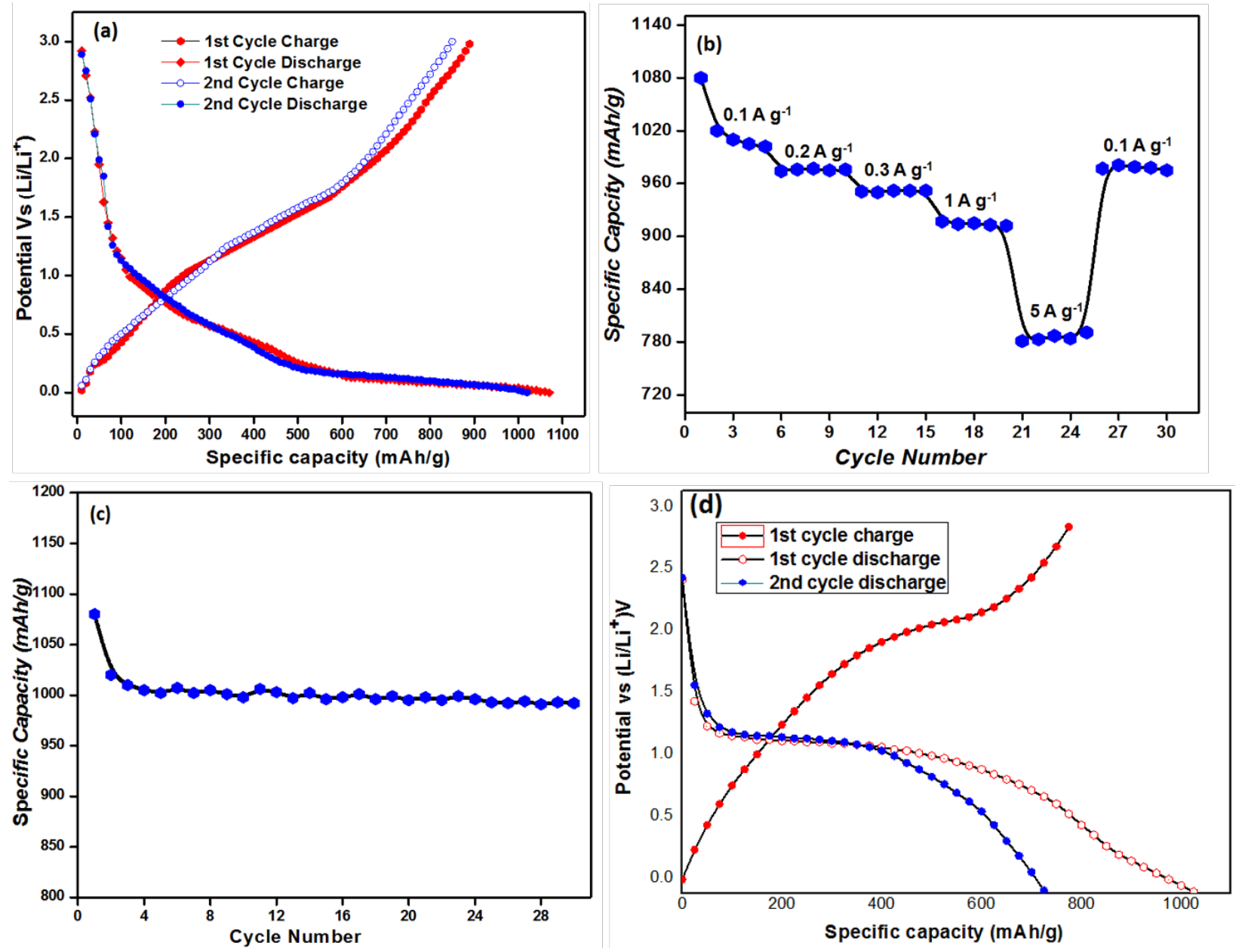

Figure 4. (a) Charge/discharge curve, (b) Cycling stability of the Co-oxide/carbon composite electrode material, (c) Rate capability performance at different current densities 
Table 1: Comparison of different electrode materials and their LIBs performance

\begin{tabular}{|c|c|c|c|c|c|}
\hline Electrode materials & $\begin{array}{l}1^{\text {st }} \text { cycle } \\
\text { discharge } \\
\left(\mathrm{mAh} \mathrm{g}^{-1}\right)\end{array}$ & $\begin{array}{l}\text { Columbic } \\
\text { efficiency } \\
\text { (\%) }\end{array}$ & $\begin{array}{l}\text { Reversible } \\
\text { capacity } \\
\text { (cycle) } \\
\left(\mathrm{mAh} \mathrm{g}^{-1}\right)\end{array}$ & $\begin{array}{l}\text { Current } \\
\text { density (mA } \\
\mathrm{g}^{-1} \text { ) }\end{array}$ & Ref. \\
\hline$\overline{\mathrm{CoO} / \mathrm{N}-\mathrm{CNTs}}$ & 1250 & 83 & $1100(50)$ & 100 & {$[16]$} \\
\hline Porous carbon spheres & 1213 & - & $506(50)$ & 100 & [27] \\
\hline $\begin{array}{l}\text { High concentration of Nitrogen } \\
\text { doped-CNTs }\end{array}$ & 730 & 68 & $494(100)$ & 100 & [28] \\
\hline $\begin{array}{l}\mathrm{N} \text {-doped graphene/Fe-Fe } \mathrm{F}_{3} \mathrm{C} \\
\text { nanocomposite }\end{array}$ & 904 & 24.6 & $1098(48)$ & 100 & [29] \\
\hline Co-doped ZnO coated with carbon & 1663 & - & $725(50)$ & 100 & [30] \\
\hline $\begin{array}{l}\mathrm{Co}_{3} \mathrm{ZnC} / \mathrm{N} \text {-doped carbon hybrid } \\
\text { nanospheres }\end{array}$ & 1570 & 58.1 & $-(60)$ & 100 & [31] \\
\hline $\mathrm{Co}_{3} \mathrm{O}_{4} / \mathrm{CNT}$ & 1478 & 81.0 & $873(50)$ & 100 & [32] \\
\hline $\mathrm{Co}_{3} \mathrm{O}_{4} /$ graphenenanocomposite & 1433 & 49.1 & $631(50)$ & 55 & [33] \\
\hline $\mathrm{Co}_{3} \mathrm{O}_{4} / \mathrm{C}$ composite & 1170 & 76.0 & $900(30)$ & 100 & {$[34]$} \\
\hline $\mathrm{Co}_{3} \mathrm{O}_{4}$ arrays & 1200 & 80.0 & $600(100)$ & 400 & [35] \\
\hline $\mathrm{Co}_{3} \mathrm{O}_{4}$ nanoneedles & 1542 & 71.3 & $813(20)$ & $0.5 \mathrm{C}$ & [36] \\
\hline $\mathrm{CoO} / \mathrm{N}-\mathrm{CNTs}$ & 1250 & 83 & $1100(50)$ & 100 & [16] \\
\hline $\mathrm{Co}_{3} \mathrm{O}_{4} / \mathrm{TiO}_{2}$ & 632.5 & - & $602.8(480)$ & 200 & [37] \\
\hline $\begin{array}{l}\text { Doped hollow porous grapheme } \\
\text { (DPHG) }\end{array}$ & 2300 & - & $900(100)$ & 100 & [38] \\
\hline b-Co(OH $)_{2} /$ grapheme hybrid & 944 & 97 & $640(150)$ & 100 & [39] \\
\hline GC-Co(OH $)_{2}$ & 1146 & - & $706(50)$ & 58 & [40] \\
\hline $\mathrm{NiO} / \mathrm{GNS}$ & 1398 & - & $982(50)$ & 100 & {$[41]$} \\
\hline $\mathrm{Co}(\mathrm{OH})_{2} / \mathrm{Co}_{3} \mathrm{O}_{4}$ hybrid & 1452 & 73.42 & $1160(40)$ & 58 & [42] \\
\hline Quadrate tubular $\mathrm{Co}_{3} \mathrm{O}_{4}$ nanoboxes & 1447 & - & $1240(50)$ & 200 & [43] \\
\hline ZnO@C/CNT & 1551 & - & $758(100)$ & 100 & [44] \\
\hline $\mathrm{CNT@ \textrm {Co } _ { 3 } \mathrm { O } _ { 4 }}$ & 850 & - & - & - & [45] \\
\hline $\mathrm{Co}_{3} \mathrm{O}_{4}$ nanobelts & 1400 & - & $980(60)$ & 100 & [46] \\
\hline $\mathrm{CoO}$ nanoporous array on $\mathrm{TiO}_{2}$ & 903 & 70 & $670(20)$ & $1 \mathrm{C}$ & [47] \\
\hline $\mathrm{Co}_{3} \mathrm{O}_{4}$ nanocages & 1025 & 61 & $970(30)$ & - & {$[48]$} \\
\hline $\mathrm{Co}_{3} \mathrm{O}_{4}$ nanoplates & 1100 & 65 & $597(100)$ & 1000 & [49] \\
\hline $\mathrm{Co}_{3} \mathrm{O}_{4}$ nanotubes & 856 & - & $677(60)$ & $1 \mathrm{C}$ & [50] \\
\hline Co-oxides/carbon composite & 1080 & 94 & $980(30)$ & 100 & $\begin{array}{l}\text { Present } \\
\text { work }\end{array}$ \\
\hline
\end{tabular}


$\underline{\text { Graphical Abstract }}$
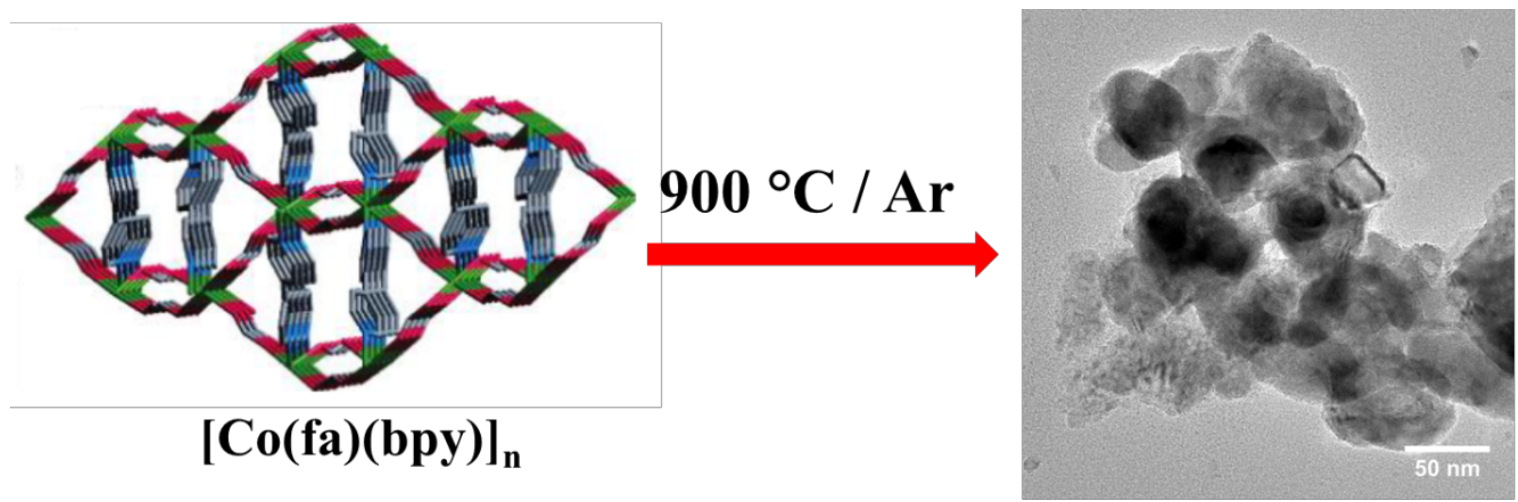

Cobalt-oxide/C composite
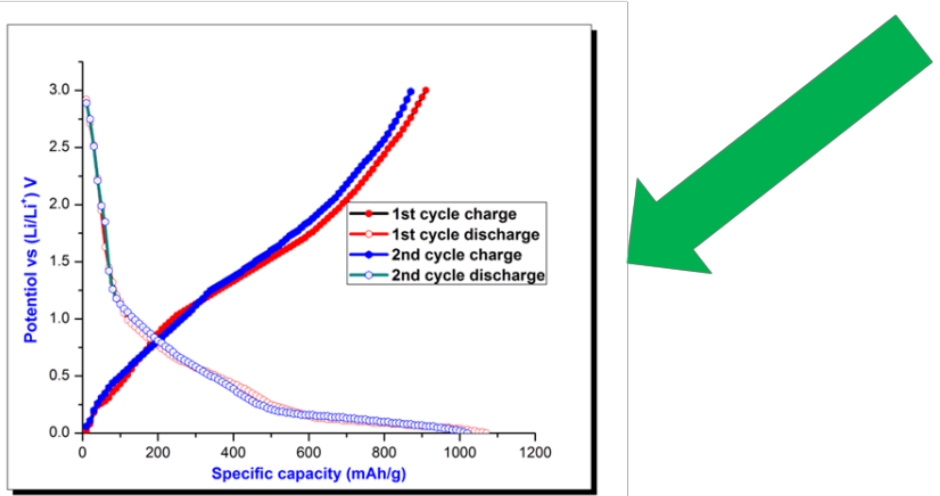